Original Scientific Article

\title{
HEMATOLOGICAL AND BIOCHEMICAL PARAMETERS IN SYMPTOMATIC AND ASYMPTOMATIC LEISHMANIA-SEROPOSITIVE DOGS
}

\author{
Igor Ulchar ${ }^{1}$, Irena Celeska ${ }^{1}$, Jovana Stefanovska $^{2}$, Anastasija Jakimovska ${ }^{1}$ \\ ${ }^{1}$ Department of Pathophysiology, Faculty of Veterinary Medicine - Skopje, \\ Ss Cyril and Methodius University, Skopje \\ ${ }^{2}$ Department of Parasitology, Faculty of Veterinary Medicine - Skopje, \\ Ss Cyril and Methodius University, Skopje
}

Received 16 April 2015; Received in revised form 22 May 2015; Accepted 28 May 2015

\begin{abstract}
Leishmaniosis caused by Leishmania infantum is vector-born severe enzootic disease in dogs. It includes a wide spectrum of clinical symptoms, but the most characteristic are alterations in the hematopoetic system and renal failure. Also, infected animals could be asymptomatic, so the manifestation of $L$. infantum infection depends on many factors, including host's immunological status. The aim of this survey was to find parameters related with hematopoetic and renal failure (hematology, biochemical parameters - urea, creatinine, serum proteins) in symptomatic and asymptomatic dogs seropositive for canine leishmaniosis. Within the hematological parameters, we found significant differences between symptomatic and asymptomatic dogs in the erythrogram and platelet count, but not in the leukogram. Significant differences between the two groups were found also for urea, creatinine, serum albumin and globulin, but not in serum total protein and A/G ratio. These findings indicate individual variability of the host's response to infection with $L$. infantum.
\end{abstract}

Key words: leishmaniosis, dog, hematology, biochemistry

\section{INTRODUCTION}

Canine leishmaniosis (CanL) is a disease caused by an intracellular protozoan of the genus Leishmania that is transmitted to the dog by the bite of some species of the bloodsucking sand flies from the genera Phlebotomus in Europe and Asia and Lutzomyia in Central and South America $(1,2,3)$. The life cycle of Leishmania parasite is biphasic with two morphological stages known as promastigotes and amasitgotes. Procyclic promastigotes are attached to the midgut epitehelial cells of Phlebotomus or Lytzomia female sandflyes,

Corresponding author: Prof. Igor Ulchar, $\mathrm{PhD}$

E-mail address: iulcar@fvm.ukim.edu.mk

Present address: Faculty of Veterinary Medicine - Skopje

Ss Cyril and Methodius University, Skopje

Lazar Pop-Trajkov 5/7, 1000 Skopje, R. of Macedonia

Phone: +38923240782; Fax: +38923114619

Copyright: (C) 2015 Ulchar I. This is an open-access article published under the terms of the Creative Commons Attribution License which permits unrestricted use, distribution, and reproduction in any medium, provided the original author and source are credited.

Competing Interests: The authors have declared that no competing

interests exist.

Available Online First: 9 June 2015

http://dx.doi.org/10.14432/j.macvetrev.2015.06.045 where after replication they differentiate into an infective metacyclic form in the anterior midgut. They are inoculated into the mammalian host by bloodsucking where they transform into amastigotes in macrophages and related cells $(4,5)$.

The most important species for the dogs is L. infantum in the Old World which is synonymous to L. chagasi in Central and South America (1). Dogs are considered the main reservoir of $L$. infantum for humans (6). CanL is one of the major zoonoses globally causing severe fatal disease in humans. Clinical manifestation of canine leishmaniosis includes a wide spectrum of clinical symptoms, which in dogs ranges from absence of symptoms to generalized disorders that may result in the host death: fever, anemia, lymphadenopathy, weight loss, emaciation, hepatosplenomegaly, conjunctivitis, renal alterations, keratitis, onychogryphosis and cutaneous lesions $(1,3,7,8,9)$. Some other organs and systems could also be involved, like heart (10), testis (11), joints (12), liver $(13,14)$ and brain (7). L. infantum is also found in the gastrointestinal system $(15,16)$, including tongue (17). 
Leishmania is able to evade the host's nonspecific defenses (phagocytosis) to survive and multiply in the macrophage. The progress of the infection depends on the efficiency of the host's immune response. There are two defense effector mechanisms which take part against Leishmania parasites: the first one is the release of superoxide $\left(\mathrm{O}_{2}^{-}\right)$by the neutrophils and macrophages via the NADPH oxidase complex (18), and the second one is the parasiticidal effect of nitric oxide (NO), mediated by interferon (IFN- $\gamma$ ) and tumor necrosis factor (TNF- $\alpha$ ) released by macrophages $(1,8,18,19,20$, $21,22)$. The opposite effect is disease susceptibility manifested with depressed cell mediated immunity with a mixed Th1 and Th2 cytokines response $(1,18)$. These cytokines are transforming growth factor (TGF- $\beta$ ), IL-10 (18) and iron regulatory protein 2 (IRP2) (22). Affected animals could show decreased antioxidant enzyme activity (23).

The majority of dogs infected with Leishmania do not always develop clinical signs (1). Furthermore, seropositivity absence does not prove that a dog is negative for Leishmania, because clinically healthy infected dogs could be negative for anti-Leishmania antibodies, but positive for Leishmania by PCR protocols $(24,25)$. This fact confirms the importance of asymptomatic dogs with Leishmania, because they obviously play a role in the transmission of Leishmania parasites. It remains unclear what are the reasons which make one dog resistible or susceptible to the disease. The clinical manifestation of CanL is complex, with many factors involved (age, gender, nutrition, host genetics, coinfections and/or concomitant disease, immunosuppressive conditions, etc.) (1).

As mentioned above, CanL has very variable clinical manifestations, and many different organs could be involved. For this reason, some laboratory tests are necessary for confirming the diagnosis, among them the complete blood count (CBC) and biochemical profile, especially for evaluation of the renal function. The most important and constant hematological change in cases of canine visceral leishmaniosis is non-regenerative anemia $(3,24,25)$. Leishmaniosis also causes changes in the white blood cell count (WBC) $(3,24,25,26)$ and thrombocytopenia (1) and even in the disseminated intravascular coagulation (DIC) (27). Another important finding related to CanL is hyperproteinemia, hypoalbuminemia, and decreased albumin/globulin ratio $(1,3,8,26)$. The severe form of CanL is characterized by renal damage with glomerulonephritis due to immune complex deposition, but there are findings which propose involvement of some other mechanisms too, like migration of T cells into the glomeruli, participation of adhesion molecules, and diminished apoptosis of cells (28). The antibodies involved in the formation of these immune complexes are unknown, although antiactin and antitubulin antibodies are found in dogs with CanL caused by L. donovani (29). Renal dysfunction could be the only clinical manifestation of the CanL and immunoinduced glomerulonephritis could progress into chronic renal failure (CRF), which is the principal cause of animal death in CanL (1). So, it is very important for renal disease to be diagnosed early, because it allows better prognosis for the patient and may prolong its life. Despite the high prevalence of renal involvement in the pathogenesis of CanL, azotemia which is typical for renal failure is evident only when the majority of nephrons have become dysfunctional in the final phase of the disease progression.

Majority of the reports are dealing with the seroprevalence of $L$. infantum in dog population $(30,31,32)$, while it still remains unclear how the biochemical and hematological status of dogs naturally infected with CanL can be associated with the clinical forms of CanL. The aim of this study was to find some of these parameters: erythrogram, leukogram, biochemical parameters associated with renal function and biochemical parameters associated with plasma protein status in symptomatic and asymptomatic dogs seropositive for CanL.

\section{MATERIAL AND METHODS}

This survey was done on a heterogeneous dog population, which included dogs from different breeds and mongrel dogs, with age ranging from 1.5 to 12 years. All investigated dogs were seropositive for CanL, which was confirmed with an indirect fluorescent antibody test (IFAT) (Figure 1). IFAT was performed according to the OIE manual (33). Promastigotes of $L$. infatnum (zymodem MON-1 9MCAN/HR/2003/LLM-1282) isolated from a dog were used for preparation of "in house" antigen. Parasites were fixed with acetone on IFAT slides (according the procedure described in OIE manual) and dog's serums were tested at starting dilution of 1:40, using FITC labeled goat anti-canine IgG $(\mathrm{H}+\mathrm{L})$ (Southern Biotech, USA). Based on the previous experiences a titer of 1:80 was considered as positive. Commercial positive and negative control serums (VMRD, cat no. 211-P-LSH and 211-N-LSH) were used for verification of the test results. 


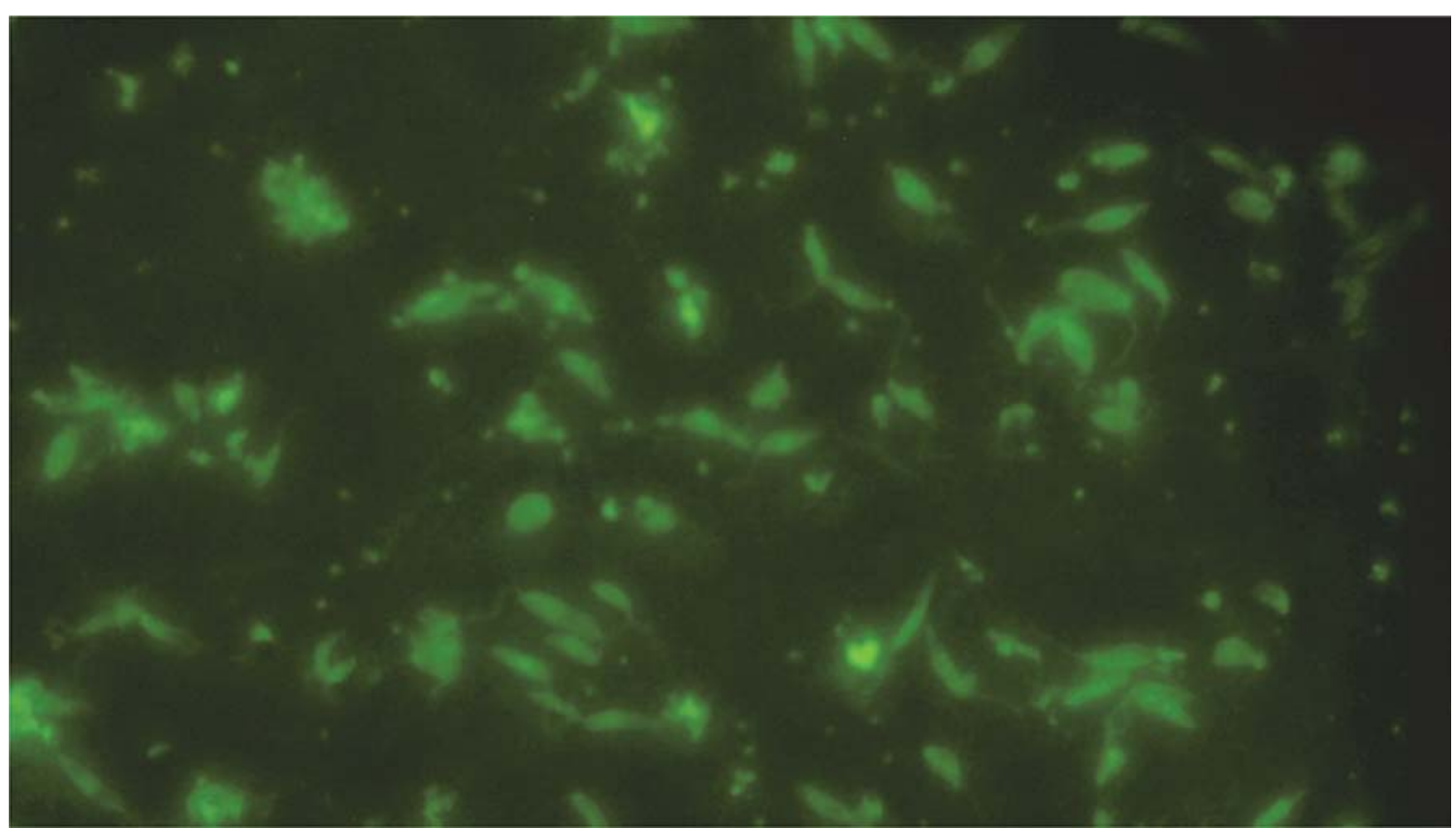

Figure 1. IFAT positive slide (promastigotes with the whole body fluorescence)

There were two groups: one manifesting clinical signs of the disease (symptomatic dogs - SD), and the other group which were dogs infected with L. infantum, but without clinical signs of leishmaniasis (asymptomatic dogs - AD). The survey included 42 dogs in total, 21 in the symptomatic and 21 in the asymptomatic group, respectively. Dogs were classified as symptomatic when manifesting at least one of the clinical symptoms classified by Solano-Gallego et al. (2011) (34).

Hemogram analyses included the following parameters: red blood cell count (RBC), hematocrit, hemoglobin concentration, mean corpuscular volume (MCV), mean corpuscular hemoglobin $(\mathrm{MCH})$, mean corpuscular hemoglobin concentration (MCHC), white blood cell count (WBC) and platelet count. Biochemical parameters investigated in this survey where those related with renal function (urea and creatinine), and protein status (total protein - TP, albumin - ALB, globulin - GLO and albumin/globulin ratio - A/G), respectively. IFAT test was done at the Laboratory of Parasitology, and hemogram and biochemical parameters testing were done at the Laboratory of Hematology and Clinical Biochemistry, within the Faculty of Veterinary Medicine in Skopje.

Blood samples for laboratory analysis were collected from V. cephalica antebrachii externa. Samples for hematology testing were taken in VACUETTE $^{\circledR}$ EDTA Tubes (Greiner Bio-One), coated with $\mathrm{K}_{3}$ EDTA and samples for biochemistry testing were taken VACUETTE ${ }^{\circledR}$ Serum Collection
Tubes (Greiner Bio-One). Hematological parameters were analyzed on hematology counter SYSMEX 2200 (Germany), according to the standard operative procedure. Biochemical parameters were analyzed on semiautomatic photometer STAT FAX 3300 (Awareness Technology, Inc. USA), Analyses of urea and creatinine were made with standard colorimetric kinetic methods, using commercial kits from Human (Germany), according to the International Federation of Clinical Chemistry and Laboratory Medicine (IFCC) propositions. Analyses of total protein and albumin were made with standard colorimetric biochemical "end-point" methods, also with commercial kits from Human (Germany). Globulin values were estimated using the difference between total protein value and albumin value.

Statistical analysis of gained data included descriptive statistics (mean - M; standard deviation - SD; standard error - SE; minimum and maximum - Min-Max; coefficient of variation $\mathrm{CV}$ ) and Student t-test for evaluation of statistical significance of variables' means. Statistical operations were made with STATISTICA for Windows 8.0 (Stat Soft Inc) software.

\section{RESULTS}

The values of hematological parameters for both groups of dogs (AD and SD) are shown in Table 1. 
Table 1. Hematological parameters: red blood cell count $\left(\mathrm{RBC} / 10^{12} / \mathrm{L}\right)$, hematocrit $(\mathrm{HCT} / \%)$, hemoglobin (HGB/g/dL), MCV (fL), MCH (pg), MCHC (g/dL), white blood cell count (WBC/10 $/ \mathrm{L}$ ) and platelet count (PLT/10 $/ \mathrm{L})$ in asymptomatic and symptomatic dogs infected with L. infantum

\begin{tabular}{ccccccccc}
\hline & \multicolumn{3}{c}{ asymptomatic dogs (AD) } & \multicolumn{4}{c}{ symptomatic dogs (SD) } \\
\cline { 2 - 9 } & M \pm SD & SE & Min-Max & CV & M \pm SD & SE & Min-Max & CV \\
\hline RBC & $6.87 \pm 0.81^{*}$ & 0.17 & $5.52-8.32$ & 11.89 & $4.44 \pm 1.72^{*}$ & 0.37 & $1.73-8.23$ & 38.81 \\
HCT & $43.22 \pm 6.68^{*}$ & 1.45 & $29.40-55.40$ & 15.45 & $29.95 \pm 12.29^{*}$ & 2.68 & $9.20-56.70$ & 41.04 \\
HGB & $16.05 \pm 2.37^{*}$ & 0.51 & $11.90-20.80$ & 14.77 & $10.09 \pm 3.75^{*}$ & 0.81 & $3.90-18.10$ & 37.16 \\
MCV & $62.88 \pm 6.57$ & 1.43 & $52.30-74.10$ & 10.44 & $66.83 \pm 6.65$ & 1.45 & $52.90-75.40$ & 9.95 \\
MCH & $23.33 \pm 1.76$ & 0.38 & $19.80-26.60$ & 7.56 & $22.63 \pm 1.17$ & 0.25 & $21.10-26.00$ & 5.21 \\
MCHC & $37.56 \pm 5.05$ & 1.10 & $30.50-44.30$ & 13.45 & $34.85 \pm 3.87$ & 0.84 & $29.90-42.70$ & 11.12 \\
WBC & $13.46 \pm 5.25$ & 1.14 & $5.90-25.20$ & 39.04 & $11.96 \pm 7.91$ & 1.72 & $3.60-38.20$ & 66.12 \\
PLT & $288.80 \pm 98.64 *$ & 21.52 & $121.0-598.0$ & 34.15 & $194.14 \pm 151.41^{*}$ & 33.04 & $3.0-605.0$ & 77.99 \\
\hline
\end{tabular}

* Differences considered as statistically significant for $\mathrm{p}$ values $<0.05$

As shown in Table 1, statistically significant differences are found for values of RBC, HCT, HGB and PLT, i.e. asymptomatic dogs had these parameters significantly higher than symptomatic dogs.

The values of biochemical parameters for both groups of dogs (AD and SD) are shown in Table 2.

As shown in Table 2, the values of urea, creatinine and globulin are significantly higher, and values of albumin are significantly lower in symptomatic dogs, compared with those in group of asymptomatic dogs.

\section{DISCUSSION}

As mentioned above, CanL is a disease with a very variable and complex clinical manifestation, where many different factors are involved. Infection itself does not always cause clinical disease, which is evident in the fact that prevalence of CanL in the endemic regions is lower than $10 \%$ (1). Whether the infected animal would remain resistible or a development of clinical disease would occur, depends on many factors, but most important is the immune status of the animal. So, the asymptomatic dogs infected with $L$. infantum are very important as a reservoir of the parasite. Although the clinical symptoms of CanL are very variable, major disorders are related to the hematopoietic system and renal function.

Our findings of RBC value in asymptomatic dogs indicate an equilibrium of erythropoiesis and erythrocyte destruction. The opposite finding was recorded in the group of symptomatic dogs, where the average RBC value was significantly lower $(\mathrm{p}<0.05)$, which indicates occurrence of mild to

Table 2. Biochemical parameters: urea $(\mathrm{mmol} / \mathrm{L})$, creatinine $(\mu \mathrm{mol} / \mathrm{L})$, total protein $(\mathrm{TP} / \mathrm{g} / \mathrm{L})$, albumin $(\mathrm{ALB} / \mathrm{g} / \mathrm{L})$, globulin $(\mathrm{GLO} / \mathrm{g} / \mathrm{L})$ and albumin/globulin ratio $(\mathrm{A} / \mathrm{G})$ in asymptomatic and symptomatic dogs infected with $L$. infantum

\begin{tabular}{ccccccccc}
\hline & \multicolumn{3}{c}{ asymptomatic dogs (AD) } & \multicolumn{4}{c}{ symptomatic dogs (SD) } \\
\cline { 2 - 9 } & $\mathbf{M} \pm$ SD & SE & Min-Max & CV & M \pm SD & SE & Min-Max & CV \\
\hline urea & $3.91 \pm 1.97^{*}$ & 0.43 & $1.03-9.40$ & 50.44 & $16.19 \pm 22.90^{*}$ & 4.99 & $0.96-81.20$ & 141.40 \\
creatinine & $89.43 \pm 26.43^{*}$ & 5.76 & $8.10-137.00$ & 29.55 & $228.44 \pm 302.34^{*}$ & 65.97 & $54.00-1341.00$ & 132.34 \\
TP & $69.64 \pm 14.57$ & 3.18 & $36.40-99.20$ & 20.92 & $76.07 \pm 23.34$ & 5.09 & $32.00-119.00$ & 30.68 \\
ALB & $29.00 \pm 6.80^{*}$ & 1.48 & $18.70-45.90$ & 23.47 & $22.03 \pm 5.70^{*}$ & 1.24 & $11.40-35.40$ & 25.87 \\
GLO & $40.64 \pm 15.39^{*}$ & 3.35 & $7.70-80.50$ & 37.86 & $54.04 \pm 23.05^{*}$ & 5.03 & $9.00-93.00$ & 42.65 \\
A/G & $0.9 \pm 0.72$ & 0.16 & $0.2-3.7$ & 125 & $0.6 \pm 0.53$ & 0.12 & $0.2-2.5$ & 113.2 \\
\hline
\end{tabular}

* Differences considered as statistically significant for $\mathrm{p}$ values $<0.05$ 
severe anemia, which could be a result of decreased erythropoiesis or increased hemolysis. This is also confirmed with high CV (38.81\%) in symptomatic dogs, which shows heterogeneity of symptomatic group, where the severity of anemia depends on the individual degree of affection of bone marrow. Values of MCV, MCH and MCHC did not show statistical significant difference between the two groups, which indicates the occurrence of nonregenerative normocytic normochromic anemia, as found by other authors $(3,24,25)$. Infection with $L$. infantum causes normocytic normochromic anemia (8), but anemia caused with $L$. donovani complex is normocytic hypochromic (3). The non-regenerative anemia accompanying CanL is commonly explained as a consequence of chronic renal failure (CRF), but there are also findings which suggest that the decrease of erythrocytes in peripheral blood could be result of direct damage of the erythrocytes done by the parasite (3) or result of bone marrow dysfunction $(3,25,31,35,36)$.

Hematocrit (HCT) as a marker of organism hydratation degree showed statistically significant difference between two groups $(p<0.05$ ). In asymptomatic dogs high value of hematocrit indicated normal water balance regulatory mechanisms, so dehydratation does not occur. In symptomatic dogs HCT was significantly lower, which is confirmed also by other authors (25). HCT decrease could be result of hemodilution, caused by decreased erythropoiesis and/or increased hemolysis, from one side, or it could be due to polydipsia, caused by high blood urea level (urea is substance with high osmolarity). Here the heterogeneity of the group is also seen, with high value of CV (41.04\%).

Hemoglobin (HGB) value was also significantly higher in asymptomatic, compared with symptomatic dogs, which is also in accordance with other surveys (25) and this finding shows difference in hemoglobin synthesis capacity in bone marrow. In asymptomatic dogs low CV (14.77\%) shows homogeneity of the group. In symptomatic dogs decreased HGB level could be explained with bone marrow dysfunction, due to high parasite load in bone marrow, or by decreased secretion of erythropoietin, caused by chronic renal failure. Here heterogeneity is also obvious, as $\mathrm{CV}$ is $37.16 \%$.

White blood cell count (WBC) did not show statistically significant difference between asymptomatic and symptomatic group, although the WBC value of the latter was insignificantly lower. Minimum-maximum range in asymptomatic dogs was very wide, probably as a result of increase of plasmocyte fraction, responsible for occurrence of polyclonal beta and gamma hyperglobulinemia, which is evident in seropositive dogs with clinical manifestation of CanL (1). Depending on clinical symptoms, in the symptomatic group which was quite heterogenic (CV 66.12\%), WBC value ranged from leukopenia, probably because of depletion of white blood cells precursors in bone marrow, to leukocytosis, in accordance with some authors (1). This leukocytosis could be result of concurrent infection with other organism from viral, bacterial (report of concurrent infection with Streptococcus equisimilis (37) or parasite origin (Erlichia canis as most common (38)). In our study average WBC value in the symptomatic group was insignificantly lower compared with asymptomatic dogs, which differs from findings reported by other authors concerning infection with $L$. infantum, where crucial signs of severe CanL are eosinopenia, lymphopenia and monocytopenia $(24,25,26)$, but is similar with those which concerned infection with $L$. donovani complex where total leukocyte count was found normal (3).

Thrombocytopenia is a common hematological finding in dogs affected with CanL (1), as it was also evident in our survey. Possible causes of this disorder are platelet sequestration, platelet consumption during clotting process, decreased or impaired production of megacariocytes and platelets, as well as immuno-mediated process.

Available data about urea and creatinine values in blood during CanL are controversial. In one survey with dogs infected with $L$. donovani complex only urea, but not creatinine was increased, indicating no renal dysfunction and this was evident only in $22.72 \%$ of dogs included in the survey (3). In another survey with dogs infected with L. infantum the finding was inverse: creatinine, but not urea was increased (26). In our survey blood urea in symptomatic dogs was significantly higher than in the asymptomatic group $(\mathrm{p}<0.05)$, and its average value was very high, beyond the referent maximum. Uremia is considered as an indicator of a late stage of severe CanL, when CRF occurs (1). This CRF is caused by immunoinduced glomerulonephritis. The extremely high CV (141.40\%) indicates again heterogeneity of the symptomatic group, where renal failure ranged from mild to severe. In asymptomatic dogs, minimum-maximum range indicates absence of renal dysfunction.

Analogous findings were obtained also for creatinine. Synthesis of creatinine in muscle tissue is relatively constant and in proportion with muscle mass, so significantly higher blood level of creatinine in symptomatic dogs $(p<0.05)$ indicates decreased renal excretion of creatinine. High CV (132.34\%) indicates heterogeneity of symptomatic group, and its maximum of $1341.00 \mu \mathrm{mol} / \mathrm{L}$ shows some 
degree of simultaneous muscle dystrophy, which could contribute to the development of CRF. In the asymptomatic group, the serum level of creatinine and its minimum-maximum range indicate regular protein catabolism and normal glomerular filtration rate (GFR).

Although most of the authors $(1,3,8,26)$ consider hyperproteinemia as important finding in CanL, in our survey the symptomatic dogs had higher serum total protein level compared with the asymptomatic group, but this difference was insignificant. In both groups the minimum-maximum range was within referent values, and $\mathrm{CV}$ was low. Also, albumin/globulin ratio $(\mathrm{A} / \mathrm{G})$ was found decreased in symptomatic dogs, but this decreasing was statistically insignificant. Both groups had high CV for $A / G$ value (125 for asymptomatic and 113.2 for symptomatic dogs, respectively), which indicates heterogeneity of each group.

However, serum albumin level in symptomatic dogs was significantly lower compared with the symptomatic group $(\mathrm{p}<0.05)$, which is in accordance with other authors' findings $(1,3,8,26)$. Normoalbuminemia found in asymptomatic dogs indicates normal protein anabolism and catabolism balance, normal hepatic function and albumin synthesis, and normal renal function, i.e. absence of albumin loss with urine (albuminuria). In symptomatic dogs evident hypoabluminemia is due to renal dysfunction, as well as the consequential albuminuria.

Changes in serum globulin in our survey are analogous to those of serum albumin. Symptomatic dogs showed significant hyperglobulinemia, which is in accordance with findings of other authors $(1,3$, $8,26)$. This hyperglobulinemia is probably caused by polyclonal beta or gamma hyperglobulinemia. Both groups showed high CV (37.86\% in asymptomatic and 42.65 in symptomatic dogs, respectively), which indicates heterogeneity of the immune response of the animal.

As mentioned above, most of the parameters investigated in this survey had high $\mathrm{CV}$ in symptomatic dogs, which suggest the heterogeneity of this group. This heterogeneity is also evident in the fact that there were no correlations found between the values of hematological and biochemical parameters.

\section{CONCLUSION}

Canine visceral leishmaniosis in the host's organism primarily affects the immune system and depending on the clinical manifestation, thed isease has an impact on thehematological and biochemical status of the animal. The pattern of host's reaction, whether asymptomatic or symptomatic with certain clinical manifestations, depends on the individual immune response. According to our findings, it could be concluded that the clinical manifestation of CanL has an impact on the erythrogram values, i.e. there is a significant difference in the erythrogram between symptomatic and asymptomatic dogs. On the other side, we found that the leukogram could not be a relevant indicator for the disease clinical progression degree in symptomatic and asymptomatic dogs seropositive for $L$. infantum. Biochemical parameters related to the renal function (urea, creatinine) could be used in making prognosis of progressed clinical leishmaniosis. The degree of proteinemia in seropositive asymptomatic and symptomatic dogs could be taken as an indicator of clinical progression of CanL only in cases of significant hyperglobulinemia. There were no correlations found between the values of hematological and biochemical parameters, which indicates individual variability of the host's response to infection with $L$. infantum.

\section{REFERENCES}

1. Solano-Gallego,L., Koutinas,A., Miró, G., Cardoso,L., Pennisi, M.G., Ferrer, L., Bourdeau, P., Oliva, G., Baneth, G. (2009). Directions for the diagnosis, clinical staging, treatment and prevention of canine leishmaniosis. Veterinary Parasitology 165, 1-18. http://dx.doi.org/10.1016/j.vetpar.2009.05.022 PMid:19559536

2. Gonçalves, R., Vieira, E.R., Melo, M.N, Gollob, K.J., Mosser, D.M, Tafuri, W.L. (2005). A sensitive flow cytometric methodology for studying the binding of L. chagasi to canine peritoneal macrophages. BMC Infectious Diseases, 5, 39.

http://dx.doi.org/10.1186/1471-2334-5-39

PMid:15913461 PMCid:PMC1166554

3. Dias, E.L., Batista, Z.S., Guerra, R.M.S.N.C., Calabrese, K.S., Lima, T.B., Abreu-Silva, A.L. (2008). Canine Visceral Leishmaniosis (CVL): Seroprevalence, clinical, hematological and biochemical findings of dogs naturally infected in an endemic area of São José de Ribamar Municipality, Maranhão State, Brazil. Ciência animal brasileira, 9(3): 740-745.

4. Bates, P.A. (2007). Transmission of Leishmania metacyclic promastigotes by phlebotomine sand flies. Int J Parasitol. 37 (10-3): 1097-1106. http://dx.doi.org/10.1016/j.ijpara.2007.04.003 PMid:17517415 PMCid:PMC2675784 
Hematological and biochemical parameters in symptomatic and asymptomatic leishmania-seropositive dogs

5. Dostálová, A, Volf, P. (2012). Leishmania development in sand flies: parasite-vector interactions overview. Parasites \& Vectors 5, 276.

http://dx.doi.org/10.1186/1756-3305-5-276

PMid:23206339 PMCid:PMC3533922

6. Gramiccia, M., Gradoni, L. (2005). The current status of zoonotic leishmaniases and approaches to disease control. Int J Parasitol. 35, 1169-1180.

http://dx.doi.org/10.1016/j.ijpara.2005.07.001

PMid:16162348

7. Sakamoto, K.P., de Melo, G.D., Machado, G.F. (2013). T and B lymphocytes in the brains of dogs with concomitant seropositivity to three pathogenic protozoans: Leishmania chagasi, Toxoplasma gondii and Neospora caninum. BMC Research Notes 6, 226. http://dx.doi.org/10.1186/1756-0500-6-226 PMid:23758819 PMCid:PMC3701587

8. Sanches, F.P., Tomokane, T.Y, Da Matta, V.L.R., Marcondes, M., Corbett, C.E.P., Laurenti, M.D. (2014). Expression of inducible nitric oxide synthase in macrophages inversely correlates with parasitism of lymphoid tissues in dogs with visceral leishmaniosis. Acta Vet. Scand. 56, 57.

http://dx.doi.org/10.1186/s13028-014-0057-z PMid:25195062 PMCid:PMC4172852

9. Verçosa, B.L.A., Lemos, C.M., Mendonça, I.L., Silva, S.M.M.S., de Carvalho, S.M., Goto, H., Costa, F.A.L. (2008). Transmission potential, skin inflammatory response, and parasitism of symptomatic and asymptomatic dogs with visceral leishmaniosis. BMC Veterinary Research 4, 45.

http://dx.doi.org/10.1186/1746-6148-4-45

PMid:18990238 PMCid:PMC2613136

10. López-Peña, M., Alemañ, N., Muñoz, F., Fondevila, D., Suárez, M.L., Goicoa, A., Nieto, J.M. (2009). Visceral leishmaniosis with cardiac involvement in a dog: a case report. Acta Vet. Scand., 51, 20.

http://dx.doi.org/10.1186/1751-0147-51-20

PMid:19405946 PMCid:PMC2679027

11. Manna, L., Paciello, O., Della Morte, R., Gravino, A.E. (2012). Detection of Leishmania parasites in the testis of a dog affected by orchitis: case report. Parasit Vectors 5, 216.

http://dx.doi.org/10.1186/1756-3305-5-216

PMid:23021706 PMCid:PMC3481428

12. McConkey, S.E., López, A., Shaw, D., Calder, J. (2002). Leishmanial polyarthritis in a dog. Can Vet J., 43 (8): 607-609.

PMid:12170836 PMCid:PMC339396

13. Melo, F.A., Moura, E.P., Ribeiro, R.R, Alves, C.F., Caliari, M.V., Tafuri, W.L., Calabrese, K.S., Tafuri, W.L. (2009). Hepatic extracellular matrix alterations in dogs naturally infected with Leishmania (Leishmania) chagasi. Int. J. Exp. Path. 90 (5): 538-548.

http://dx.doi.org/10.1111/j.1365-2613.2009.00681.x PMid:19765108 PMCid:PMC2768152
14. Silva, L.C., Castro, R.S, Figueiredo, M.M., Michalick, M.S.M., Tafuri, W.L., Tafuri, W.L. (2013). Canine visceral leishmaniosis as a systemic fibrotic disease. Int. J. Exp. Path. 94 (2): 133-143.

http://dx.doi.org/10.1111/iep.12010

PMid:23419132 PMCid:PMC3607142

15. Figueiredo,M.M.,Deoti,B.,Amorim,I.F.,Pinto,A.J.W., Moraes, A., Carvalho, C.S., da Silva, S.M., de Assis, A.C. B., de Faria, A.M.C., Tafuri, W.L. (2014). Expression of regulatory $\mathrm{T}$ cells in jejunum, colon, and cervical and mesenteric lymph nodes of dogs naturally infected with Leishmania infantum. Infect Immun., 82 (9): 3704-3712.

http://dx.doi.org/10.1128/IAI.01862-14

PMid:24935975 PMCid:PMC4187817

16. Pinto,A.J.W.,Figueiredo,M.M., Silva,F.L., Martins, T., Michalick, M.S.M., Tafuri, W.L., Tafuri, W.L. (2011). Histopathological and parasitological study of the gastrointestinal tract of dogs naturally infected with Leishmania infantum. Acta Vet Scand, 53, 67. http://dx.doi.org/10.1186/1751-0147-53-67

PMid:22166041 PMCid:PMC3269393

17. Viegas, C., Requicha, J., Albuquerque, C., Sargo T., Machado J., Dias I., Pires, M.A., Campino, L., Cardoso, L. (2012). Tongue nodules in canine leishmaniosis - a case report. Parasit Vectors 5, 120. http://dx.doi.org/10.1186/1756-3305-5-120 PMid:22704596 PMCid:PMC3407507

18. Bogdan, C., Röllinghoff, M. (1998). The immune response to Leishmania: mechanisms of parasite control and evasion. Int J Parasitol, 28 (1): 121-134. http://dx.doi.org/10.1016/S0020-7519(97)00169-0

19. Loría-Cervera, E.N., Andrade-Narváez, F.J. (2014). Animal Models for the Study of Leishmaniosis Immunology. Rev. Inst. Med. Trop. Sao Paulo, 56 (1): $1-11$.

http://dx.doi.org/10.1590/S0036-46652014000100001 PMid:24553602 PMCid:PMC4085833

20. Pinelli, E., Killick-Kendrick, R., Wagenaar, J., Bernadina, W., del Real, G., Ruitenberg, J. (1994). Cellular and humoral immune responses in dogs experimentally and naturally infected with Leishmania infantum. Infect Immun., 62 (1): 229-235. PMid:8262632 PMCid:PMC186091

21. Pinelli, E., Rutten, V.P.M.G., Bruysters, M., Moore, P.F., Ruitenberg, E.J. (1999). Compensation for decreased expression of B7 molecules on Leishmania infantuminfected canine macrophages results in restoration of parasite-specific T-cell proliferation and gamma interferon production. Infect Immun., 67 (1): 237-243. PMid:9864221 PMCid:PMC96302

22. do Nascimento, P.R.P., Martins, D.R.A., Monteiro, G.R.G., Queiroz, P.V., Freire-Neto, F.P., Queiroz, J.W., Lima, Á.L.M., Jeronimo, S.M.B. (2013). Association of pro-inflammatory cytokines and iron regulatory protein 2 (IRP2) with Leishmania burden in canine visceral leishmaniosis. PLoS One 8(10): e73873. http://dx.doi.org/10.1371/journal.pone.0073873 
23. Souza, C.C., Barreto, T.O., da Silva, S.M., Pinto, A.W. J., Figueiredo, M.M., Rocha, O.G.F., Cangussú, S.D., Tafuri, W.L. (2014). A potential link among antioxidant enzymes, histopathology and trace elements in canine visceralleishmaniosis. Int.J.Exp.Path.,95(4):260-270. http://dx.doi.org/10.1111/iep.12080

PMid:24766461 PMCid:PMC4170968

24. Coura-Vital, W., Marques, M.J., Giunchetti, R.C., Teixeira-Carvalho,A., Moreira,N.D., Vitoriano-Souza,J., Vieira, P.M., Carneiro, C.M., Corrêa-Oliveira, R., Martins-Filho, O.A., Carneiro, M., Reis, A.B. (2011). Humoral and cellular immune responses in dogs with inapparent natural Leishmania infantum infection. Vet J. 190 (2), e43-e47.

http://dx.doi.org/10.1016/j.tvj1.2011.04.005 PMid:21596598

25. Nicolato, R.deC., de Abreu, R.T., Roatt, B.M., Aguiar-Soares, R.D.O., Reis, L.E.S., Carvalho, M.G., Carneiro, C.M., Giunchetti, R.C., Bouillet, L.E.M., Lemos, D.S, Coura-Vital, W., Reis, A.B. (2013). Clinical forms of canine visceral leishmaniosis in naturally leishmania infantum-infected dogs and related myelogram and hemogram changes. PLoS One. 8 (12): e82947.

http://dx.doi.org/10.1371/journal.pone.0082947

26. Kargin Kiral, F., Seyrek, K., Pasa, S., Ertabaklar, H., Ünsal, C. (2004). Some haematological, biochemical and electrophoretic findings in dogs with visceral leishmaniosis. Revue Méd. Vét., 155 (4): 226-229.

27. Honse, C.O., Figueiredo, F.B., de Alencar, N.X., Madeira, M.deF., Gremião, I.D.F, Schubach, T.M.P. (2013). Disseminated intravascular coagulation in a dog naturally infected by Leishmania (Leishmania) chagasi from Rio de Janeiro - Brazil. BMC Veterinary Research 9, 43.

http://dx.doi.org/10.1186/1746-6148-9-43

PMid:23497531 PMCid:PMC3599858

28. Costa, F.A.L., Prianti, M.G., Silva, T.C., Silva, S.M.M.S., Guerra, J.L., Goto, H. (2010). T cells, tadhesion molecules and modulation of apoptosis in visceral leishmaniosis glomerulonephritis. BMC Infect Dis., 10, 112.

http://dx.doi.org/10.1186/1471-2334-10-112

29. Pateraki, E., Portocala, R., Labrousse, H., Guesdon, J.-L. (1983). Antiactin and antitubulin antibodies in canine visceral leishmaniosis. Infect Immun. 42 (2): 496-500.

PMid:6642639 PMCid:PMC264456

30. Menn, B., Lorentz, S., Naucke, T.J. (2010). Imported and travelling dogs as carriers of canine vector-borne pathogens in Germany. Parasit Vectors, 3, 34. http://dx.doi.org/10.1186/1756-3305-3-34 PMid:20377872 PMCid:PMC2857866
31. Momo, C., Jacintho, A.P.P., Moreira, P.R.R., Munari, D.P., Machado, G.F., Vasconcelos, R.deO. (2014). Morphological changes in the bone marrow of the dogs with visceral leishmaniosis. Vet Med Int., 150582 .

http://dx.doi.org/10.1155/2014/150582

PMid:24744957 PMCid:PMC3972870

32. Živičnjak, T., Martinković, F., Marinculić, A., Mrljak, V., Kučer, N., Matijatko, V., Mihaljević, Ž., Barić-Rafaj, R. (2005). A seroepidemiologic survey of canine visceral leishmaniosis among apparently healthy dogs in Croatia. Vet Parasitol. 131 (1-2): 35-43. http://dx.doi.org/10.1016/j.vetpar.2005.04.036 PMid:15946800

33. Office International des Epizooties (OIE) (2008). Manual of standards diagnostic tests and vaccines, Part 2, Section 2.2, Chapter 2.2.11.: Leishmaniosis.

34. Solano-Gallego,L., Miró, G., Koutinas,A., Cardoso,L., Pennisi, M.G., Ferrer, L., Bourdeau, P., Oliva, G., Baneth, G. (2011). LeishVet guidelines for the practical management of canine leishmaniosis. Parasites \& Vectors 4, 86.

http://dx.doi.org/10.1186/1756-3305-4-86 PMid:21599936 PMCid:PMC3125381

35. Trópia de Abreu, R., Carvalho, M.dG., Carneiro, C.M., Giunchetti, R.C., Teixeira-Carvalho, A., Martins-Filho, O.A., Coura-Vital, W., Corrêa-Oliveira, R., Reis, A.B. (2011). Influence of clinical status and parasite load on erythropoiesis and leucopoiesis in dogs naturally infected with Leishmania (Leishmania) chagasi. PLoS ONE 6 (5): e18873.

http://dx.doi.org/10.1371/journal.pone.0018873

36. De Tommasi,A.S., Otranto, D., Furlanello, T., Tasca, S., Cantacessi, C., Breitschwerdt, E.B., Stanneck, D., Dantas-Torres, F., Baneth, G., Capelli, G., de Caprariis, D. (2014). Evaluation of blood and bone marrow in selected canine vector-borne diseases. Parasit Vectors. 7, 534.

http://dx.doi.org/10.1186/s13071-014-0534-2 PMid:25441458 PMCid:PMC4261574

37. Ramos-Vara,J.A., Briones, V., Segalés, J., Vilafranca, M., Sordé, A., Miller, M.A. (1994). Concurrent infection with Streptococcus equisimilis and Leishmania in a dog. J Vet Diagn Invest., 6 (3): 371-375. http://dx.doi.org/10.1177/104063879400600317

38. Mekuzas, Y., Gradoni,L., Oliva, G., Foglia Manzillo, V., Baneth, G. (2009). Ehrlichia canis and Leishmania infantum co-infection: a 3-year longitudinal study in naturally exposed dogs. Clin Microbiol Infect., 15 (Suppl. 2): 30-31.

http://dx.doi.org/10.1111/j.1469-0691.2008.02150.x PMid:19416288 